Magnetic Properties and Irreversibility Behavior in Ag-Sheathed Mi-Based

Superconducting Wires Fabricated Using a Controlled Melt Procedure*

S.X. Dou, H.K. Liu, Y.C. Guo

School of Materials Science \& Engineering

University of New South Wales, Kensington, NSW 2033 Australia

$$
\text { D.L. Shi }
$$

Materials Science Division, Argonne National Laboratory, Argonne, IL 60439

M.D. Sumption and E.W. Collings

Battelle Memorial Institute, Columbus, $\mathrm{OH} 43201$

The submitted manuscript has been authored
by a contractor of the U.S. Government under
contract No. W-31-109-ENG-38. Acoordingly,
the U.S. Government retains a nonexclusive,
royalty-free license to publish or reproduce the
published form of this contribution, or allow
others to do so, for U.S. Government purposes.

INVITED: The Fifth International Symposium on Superconductivity, International Conference Center, Kobe, Japan, November 16-19, 1992,.

jmc

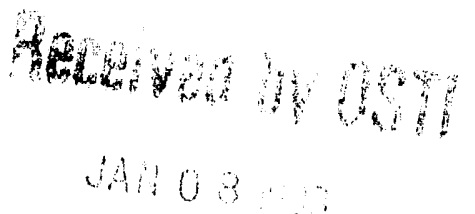

\footnotetext{
*Work supported by the Electric Power Research Institute under contract \#RP8009-06 (Battelle), the Metal Manufactu i, Ltd. (University of New South Wales), and the U.S. Department of Energy, BES-Materials Sciences unuer contract \#W-31-109-ENG-38.
} 
MAGNETIC PROPERTIES

AND IRREVERSIBILITY BEHAVIOR IN Ag-SHEATHED Bi-BASED SUPERCONDUCTING WIRES FABRICATED USING A CONTROLLED MELT PROCEDURE

by

S. X. Dou, H. K. Liu, and Y. C. Guo

School of Materials Science and Engineering

University of New South Wales

Kensington, NSW 2033, Australia

\author{
D. L. Shi \\ Materials Science Division \\ Argonne National Laboratory \\ Argonne, IL 60349, USA
}

M. D. Sumption and E. W. Collings

Battelle Memorial Institute, Columbus, OH 43201, USA

Prepared for

ISS'92

The Fifth International Symposium

on Superconductivity

International Conference Center

Kobe, JAPAN

November 16-19, 1992 


\title{
MAGNETIC PROPERTIES AND IRREVERSIBILITY BEHAVIOR IN Ag-SHEATHED Bi-BASED SUPERCONDUCTING WIRES FABRICATED USING A CONTROLLED MELT PROCEDURE
}

\author{
S. X. Dou ${ }^{\dagger}$, H. K. Liu ${ }^{\dagger}$, Y. C. Guo ${ }^{\dagger}$, D. L. Shi ${ }^{\dagger+}$, M. D. Sumption ${ }^{\text {tt, } \text { and E. W. Collings }}{ }^{\dagger \dagger}$ \\ † School of Mater. Science and Eng., Univ. of New South Wales, Kensington, NSW 2033, Australia \\ †† Materials Science Division, Argonne National Laboratory, Argonne, IL 60349, USA \\ $\dagger+\dagger$ Battelle Memorial Institute, Columbus, OH 43201, USA
}

\begin{abstract}
A significant enhancement of the in-field $\mathrm{J}_{c}$ of $\mathrm{Ag}$-clad (Bi,Pb)-Sr-Ca-Cu-O (BPSCCO:2223) wires has been achieved using a controlled melt procedure. The greatly reduced weak linking has resulted in an extended plateau regime in the $J_{c}-H$ curve. $J_{c} s$ of $40,000 \mathrm{~A} / \mathrm{cm}^{2}$ at $77 \mathrm{~K}$. (self field) and $9,000 \mathrm{ANcm}^{2}$ at $77 \mathrm{~K}(1 \mathrm{~T})$ have been achieved. The improved $\mathrm{J}_{\mathrm{c}}-\mathrm{H}$ characteristics may be attributed to microstructures consisting of uniform grain alignment throughout the entire cross section, intimate connection between grains, impurities within the grains, and an optimal level of oispersed 2212 phase. Irreversibility line measurements using both AC susceptibility in DC fields (reported elsewhere), and magnetization measurements, have indicated that flux pinning can be enhanced in the melt-processed samples over the results of normal solid-state processing with its less-than optimal 2212-phase content. But sufficiently long annealing times during the "normal" route may achieve 2212-phase content anci $j_{c} s$ which are comparable to those of melt-processed samples.
\end{abstract}

KEY WORDS: Powder-in-tube wire, BSCCO:2223 wire, critical current density, melt processing, irreversibility line, flux pinning.

\section{INTRODUCTION \\ Background}

It is well known that numerous research-and-development programs directed towards the processing of currentcarrying high- $T_{c}$ superconductors (HTSCs) are under way worldwide. It is also recognized that the powder-insilver-tube process can be counted among the most successful to date. Powder-in-tube processing (henceforth PIT processing) is being investigated in the US (several programs), in Germany (in at least two locations), and in Japan where at least seven major programs are under way. In many of these programs very high transport critical current densities have been achieved -- particularly on short lengths and mostly in the He-temperature range (4-30 $\mathrm{K}$ ). Superconductors based on the compound $\mathrm{Bi}-\mathrm{Sr}-\mathrm{Ca}-\mathrm{Cu}-\mathrm{O}$ (henceforth $\mathrm{BSCCO}$ ) have been identified as possessing outstanding potential for low-temperature high-magnetic-field applications. But numerous problems need to be solved before PIT conductors can be deemed suitable for service. Among the most pressing of them are innovative ways of introducing flux-pinning sites into BSCCO in order to raise its practical operating temperature into the liquid- $\mathrm{N}$ range.

The starting materials, initially powders of nominal composition $\mathrm{Bi}_{2} \mathrm{Sr}_{2} \mathrm{Ca}_{1} \mathrm{Cu}_{2} \mathrm{O}_{y}$ (i.e. "2212") or $(\mathrm{Bi}, \mathrm{Pb})_{2} \mathrm{Sr}_{2} \mathrm{Ca}_{2} \mathrm{Cu}_{3} \mathrm{O}_{\mathrm{y}}$ ("2223") are loaded into $\mathrm{Ag}$ tubes. Using standard deformation methods the packed tubes are reduced to wire of about $1-2 \mathrm{~mm}$ in diameter. It is then usual to flat roll the wire to ribbon, commonly 0.1 $0.3 \mathrm{~mm}$ thick. If 2212 is being processed, the ribbon is given a final carefully controlled heat treatment to promote grain growth, connectivity, and orientation. If 2223 has been selected, the ribbon is given two or more heat treatments separated by cold rolling. Of the three known superconducting BSCCO phases $-2201\left(T_{c}=20\right.$ $\mathrm{K}), 2212\left(\mathrm{~T}_{\mathrm{c}}=90 \mathrm{~K}\right)$, and $2223\left(\mathrm{~T}_{\mathrm{c}}=110 \mathrm{~K}\right)$ - only the latter two are technically viable. Of these, 2212 is the easier to form and the more thermodynamically stable. Since 2212 is simpler to prepare initially than 2223 and requires only one final heat treatment rather than 2223's several heat treatments (separated by an intermediate cold rolling) it is the preferred material for high-field operation in the liquid-He range. But if operation in $77 \mathrm{~K}$ is to become a reality, the higher- $T_{c} 2223$ material (in association with due attention to flux pinning) will be necessary.

Important contributions to progress in BSCCO:2223 PIT conductor processing have been made by researchers associated with companies and institutions such as: Mitsubishi Material Corporation (MBC) [1], Interdisciplinary Research Center in Superconductivity (IRC) $[2,4]$, Northwest Institute for Nonferrous Metal Research (NIN) [3], Toyohashi University of Technology (TTI) [4], University of Geneva (UDG) [5], Showa Electric Wire and Cable (SEW) [6], Sumitomo Electric Industries (SEl) [7-13], Kyoto University Dept. of Metallurgy (KUM) [14-16], National Research Institute for Metals (NRI) [17], Vacuumschmelze (VAC) [18-21], Argonne National Laboratory (ANL) [22,23], Intermagnetics General Corporation (IGC) [24-26], and University of New South Wales (NSW) [27-33]. 
Conventional Processing and Typical Properties of PIT BSCCO:2223

Starting Compositions and Powder Preparation: Numerous slight variants of the nominal starting-material cation-ratio of $[(\mathrm{Bi}, \mathrm{Pb})] /[\mathrm{Sr}] /[\mathrm{Ba}] /[\mathrm{Ca}] /[\mathrm{Cu}]=(2) / 2 / 2 / 3$ have been preferred by various groups. MBC employed a Bi-poor, Ca-rich $(1.3,0.4) / 2 / 2.2 / 3.1$ blend. Bi-rich but otherwise close-to-nominal ratios were employed by NIN, VAC, ANL, and NSW -- e.g. in the latter case (1.83,0.35)/1.90/2.05/3.05. Ratios that were both Bi-rich and Carich were employed by TTI, SEI, and IGC -. e.g. in the latter case $(1.8,0.4) / 2 / 2.5 / 3$. Popular powder preparation routes included: (1) the milling of mixtures of oxides and carbonates followed by calcination and further milling or grinding (ANL,IGC); (2) the co-decomposition into powder of a mixed metal nitrate solution, followed by calcination, grinding, pelletization, sintering and further grinding (NSW).

Heat Treatments and Phase Stability: The PIT fabrication sequence for BSCCO:2223 ribbon is terminated by a sequence of thermomechanical processing steps consisting of two or more heat treatments separated by cold compaction. Selection of the heat treatment temperature is critically important. Between 854 and $858^{\circ} \mathrm{C} 2223$ coexists with 2212 , while above $859^{\circ} \mathrm{C} 2212$ is the equilibrium phase. The longer the dwell time in the 2212 regime the more difficult it becomes to recover the 2223 phase during subsequent lower temperature annealing (e.g. at $834^{\circ} \mathrm{C}$ ) [33]. For this reason, heat treatment of the PIT 2223 tapes is usually performed at about $840^{\circ} \mathrm{C}$. Examples of some selected temperatures and times are: $20 \mathrm{~h} / 840^{\circ} \mathrm{C}$ (IRC), $70 \mathrm{~h} / 845^{\circ} \mathrm{C}(\mathrm{NIN}), 100 \mathrm{~h} / 815-840^{\circ} \mathrm{C}$ (TTI), $24-48 \mathrm{~h} / 845^{\circ} \mathrm{C}$ (UDG), $30-100 \mathrm{~h} / 840-850^{\circ} \mathrm{C}$ (SEI), $10-100 \mathrm{~h} / 830-845^{\circ} \mathrm{C}$ (KUM), $40 \mathrm{~h} / 840^{\circ} \mathrm{C}$ (NRI), $100 \mathrm{~h} / 830^{\circ} \mathrm{C}$ (VAC), $50-100 \mathrm{~h} / 845^{\circ} \mathrm{C}$ (ANL), $48-150 \mathrm{~h} / 840^{\circ} \mathrm{C}$ (IGC). Some heat treatments are performed in air, others in mixtures of $\mathrm{N}_{2}$ and $\mathrm{O}_{2}$.

Short-Sample Critical Current Densities: For BSCCO:2223, 4.2-K J $\mathrm{s}$ at 0 to several tens of teslas are frequently reported, as are $77-\mathrm{K} \mathrm{J}_{\mathrm{c}} \mathrm{s}$ at 0 (self-field), 0.1 , and $1 \mathrm{~T}$. The $77-\mathrm{K}$ self-field $\mathrm{J}_{\mathrm{c}}$ makes a useful benchmark number. Some typical values that have been reported in recent years are: (i) At the low end of the scale: $3.2 \mathrm{kA} / \mathrm{cm}^{2}$ (IRC), $6.3 \mathrm{kA} / \mathrm{cm}^{2}(\mathrm{SEW})$, and $9 \mathrm{kA} / \mathrm{cm}^{2}$ (ANL). (ii) Further up the scale are: $24 \mathrm{kA} / \mathrm{cm}^{2}$ (IGC), $33 \mathrm{kA} / \mathrm{cm}^{2}$ (UDG,VAC), and $54 \mathrm{kA} / \mathrm{cm}^{2}(\mathrm{SEI})$. Intermediate values were reported by $\mathrm{MBC}, \mathrm{NIN}$, TTI, and KUM.

The purpose of the present paper is to emphasize the improvement in properties that follow when 2212 phase is present. One route towards achieving this is to briefly heat the PIT ribbon to $860^{\circ} \mathrm{C}$ during three-stage thermomechanical cycling to $832-836^{\circ} \mathrm{C}$.

\section{FLUX PINNING IN PIT BSCCO:2223}

\section{Flux Pinning Microstructures}

Magnetization decay (flux creep) studies have shown that the pinning potentials of defects inherent in HTSCs are comparable to those that have been developed in practical low- $\mathrm{T}_{c}$ superconductors such as $\mathrm{Nb}_{3} \mathrm{Sn}$ [34] and presumably NbTi. However, particularly in the BSCCO HTSCs, extra pinning by defects and precipitates is needed to support supercurrents at temperatures above 30-40 K. Flux-pinning defects have been produced by irradiation [35] and cold deformation [27,29]. Flux pinning has also been introduced in the form of fine-scale

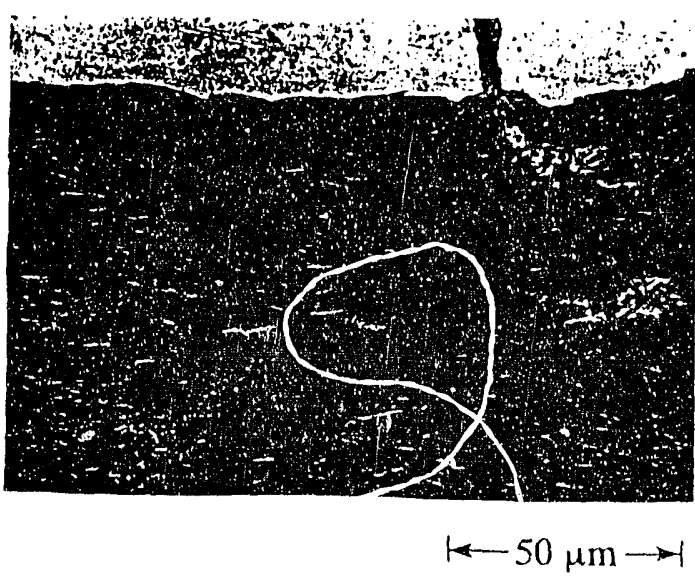

Fig. 1: Highly textured PFDR-process microstructure exhibiting uniformly elongated 2212 precipitates (white) less than $1 \mathrm{~lm}$ in thickness.

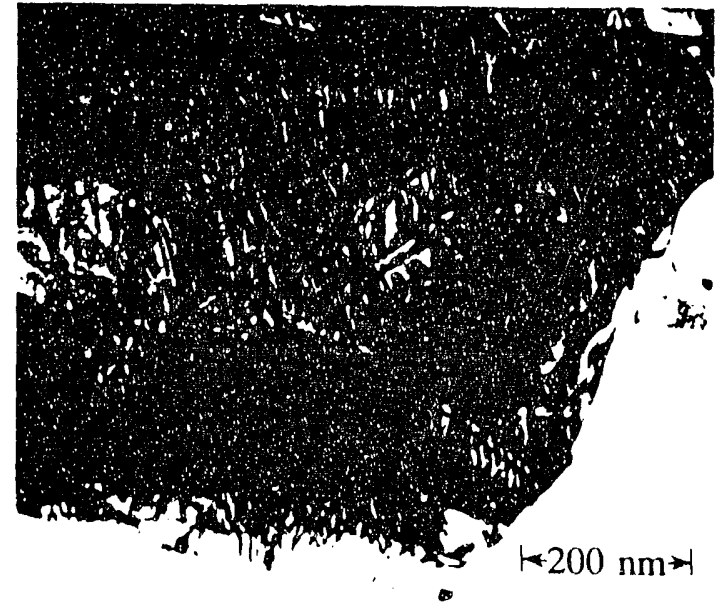

Fig. 2: TEM image taken from a PFDR-process tape showing a high density of dislocations. 


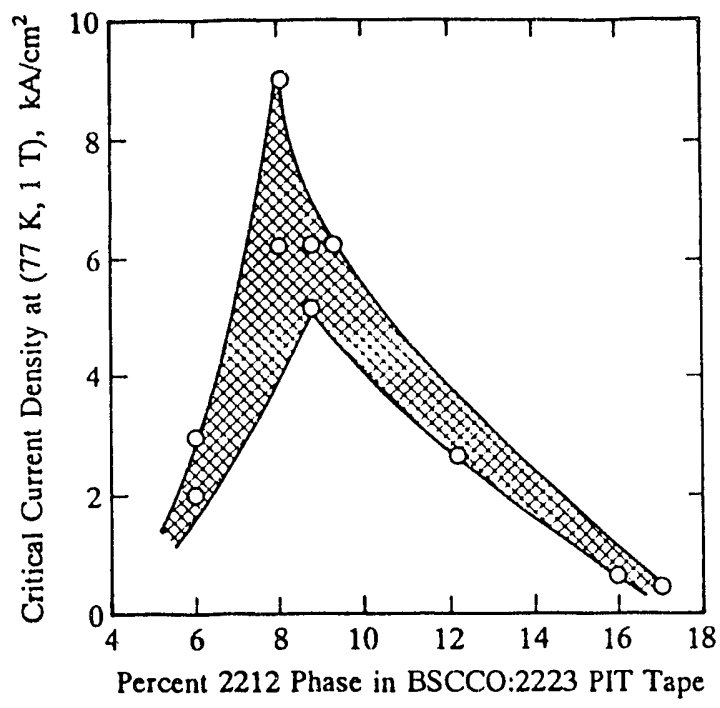

Fig. 3: Influence of 2212 abundance in a PDFRprocess tape on critical current density $(77 \mathrm{~K}, 1 \mathrm{~T})$.

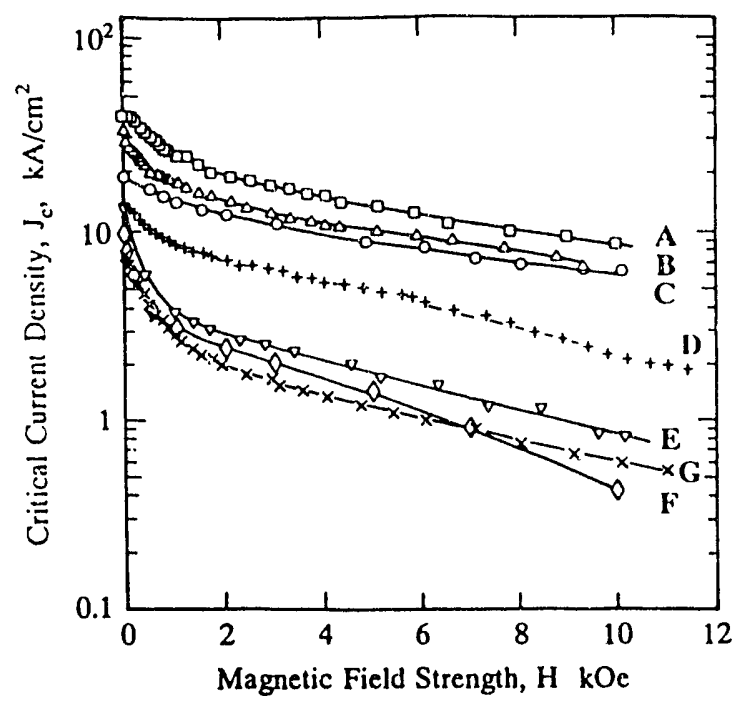

Fig. 4: $J_{c}$ versus $H$ curves for the PDFR-process tapes $\mathbf{A}, \mathbf{B}, \mathbf{C}, \mathbf{D}$, and $\mathbf{N}$-process tapes $\mathbf{E}, \mathbf{F}, \mathbf{G}$.

dispersions of $\mathrm{Ca}_{2} \mathrm{PbO}_{4}$ and (Ca,Sr)-Cu-O (SEI), and $\mathrm{MgO}$ and $\mathrm{CaO}$ precipitates (KUM). But just as $\alpha$-phase in $\mathrm{NbTi}$ and 211-phase in $\mathrm{YBaCuO}: 123$ act as "naturally occurring" flux-pinning precipitates, it was predicted that 22.12-phase should play a comparable role in 2223. To provide flux pinning without degrading the primary superconducting properties the 2212 phase must, however, be sufficiently fine and well dispersed. Dou and colleagues have achieved this goal using the "phase formation-decomposition-recovery process" (PFDR) in which a brief excursion into the molten regime at $860^{\circ} \mathrm{C}$ is inserted between several lower temperature heat treatments.

The Phase Formation-Decomposition-Recovery (PFDR) Process

A typical PFDR Process consists of three heating cycles at $832-836^{\circ} \mathrm{C}$ for $50-80 \mathrm{~h}$ for each cycle, during which a melt treatment of $15-30 \mathrm{~min}$. at $860^{\circ} \mathrm{C}$ is introduced as part of the initial segment of the second temperature cycle. $\mathrm{X}$-ray diffraction studies have revealed that the 2223 phase formed during the first cycle decomposed into 2212 and impurity phases during the second cycle then almost fully recovers during the third heating cycle [33]. The result was a textured predominantly 2223 phase matrix containing 2212 phase as fine elongated dispersants less than $1 \mu \mathrm{m}$ thick, Fig. 1, together with fine $\mathrm{CaCuO}$ and $\mathrm{SrCaCuO}$ precipitates. It is probable that lattice defects such as stacking faults and dislocations, Fig. 2, and the nonsuperconducting precipitates provide flux pinning over the entire temperature range of the 2223 matrix, and that the 2212 phase enhances that pinning in the higher temperature regime above its $T_{c}$. The optimal 2212-phase abundance secms to be about 7-10 percent, Fig. 3 .

\section{RESULTS AND DISCUSSION}

In what follows a comparison is made between the properties of several samples of PFDR-process and solid-state reacted, N-process, tapes. Some earlier measured samples, designated A, B, C, D, were prepared by the abovementioned PFDR process. Another set, E, F, G, were prepared by an N-process consisting, typically, of the above but without the upquench to $860^{\circ} \mathrm{C}$. Two recently studied samples are: (a) Sample M1, PFDR-processed according to: $\left(70 \mathrm{~h} / 830^{\circ} \mathrm{C}\right) \mathrm{p}\left(20 \mathrm{~min} / 862^{\circ} \mathrm{C}\right)\left(50 \mathrm{~h} / 825^{\circ} \mathrm{C}\right) \mathrm{p}\left(40 \mathrm{~h} / 834^{\circ} \mathrm{C}\right) \mathrm{p}\left(65 \mathrm{~h} / 834^{\circ} \mathrm{C}\right)$, and (b) Sample N1, N-processed according to: $\left(80 \mathrm{~h} / 832^{\circ} \mathrm{C}\right) \mathrm{p}\left(60 \mathrm{~h} / 832^{\circ} \mathrm{C}\right) \mathrm{p}\left(30 \mathrm{~h} / 833^{\circ} \mathrm{C}\right) \mathrm{p}\left(50 \mathrm{~h} / 833^{\circ} \mathrm{C}\right) \mathrm{p}\left(60 \mathrm{~h} / 833^{\circ} \mathrm{C}\right)$, where " $\mathrm{p}$ " indicates pressing between heat treatments.

\section{Transport Critical Current Density}

Figure 4 compares the field dependence of transport $J_{c}$ in PFDR-process and N-process tapes at $77 \mathrm{~K}$. Evidently in the low field regime, the $\mathrm{J}_{\mathrm{c}}$ for the PFDR-process tapes drops much slower than that for the N-process tapes. At low fields $(\mathrm{H}<300-500 \mathrm{Oe})$ the rapid drop in $\mathrm{J}_{\mathrm{c}}$ is attributed to Josephson weak links at grain boundaries. The $\mathrm{N}$-process tapes lose more than $75 \%$ to $80 \%$ of their zero-field $\mathrm{J}_{\mathrm{c}} \mathrm{s}$ at $0.1 \mathrm{~T}$, whereas the PFDR-process tapes lose only $25 \%$ to $43 \%$, indicating a significant reduction in weak link behavior. At $1 T$ the best PFDR-process tapes retain $33 \%$ of their zero-field $J_{c}$ while the $\mathrm{N}$-process tapes retain only $10 \%$. Thus at $1 \mathrm{~T}$ the PFDR-process tapes would be expected to show a 3- to 10 -fold higher $\mathrm{J}_{\mathrm{c}}$ than their $\mathrm{N}$-process counterparts.

Summary of PFDR $J_{c}$ Properties: PFDR-process tape can possess $77-\mathrm{K} \mathrm{J} s$ of $40 \mathrm{kA} / \mathrm{cm}^{2}$ at $0 \mathrm{~T}, 25 \mathrm{kA} / \mathrm{cm}^{2}$ at $0.1 \mathrm{~T}$, and $9 \mathrm{kA} / \mathrm{cm}^{2}$ at $1 \mathrm{~T}$; its $\mathrm{J}_{\mathrm{c}}$ shows an extended plateau from 0.1 to $1 \mathrm{~T}$. 


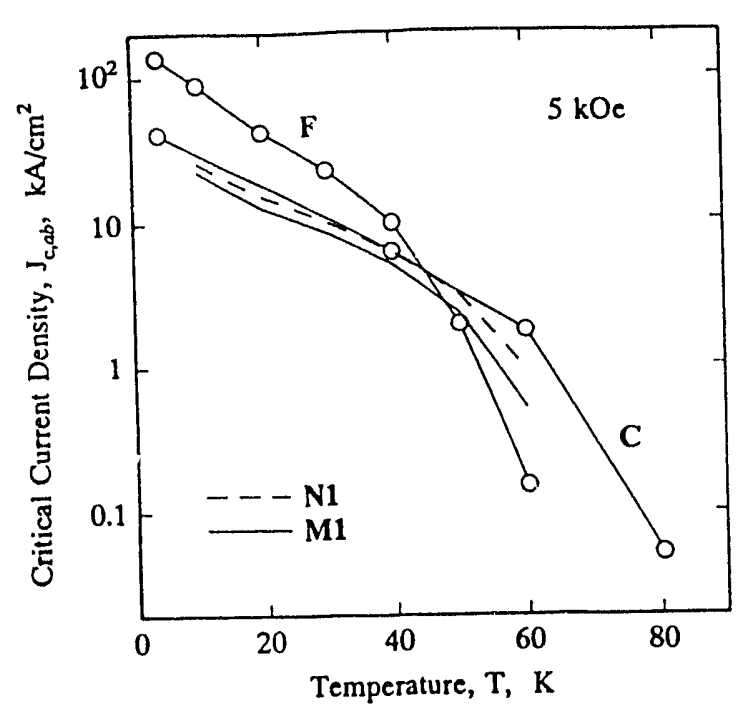

Fig. 5: Magnetic $\mathrm{J}_{c a b}(5 \mathrm{kOe})$ versus $\mathrm{T}$ for the PDFR-process tape $\mathbf{C}$ and the $\mathrm{N}$-process tape $\mathbf{F}$. Inserted are $\mathrm{J}_{\mathrm{c}_{a}, b}(5 \mathrm{kOe})$ data for $\mathrm{M1}$ and $\mathrm{N} 1$.

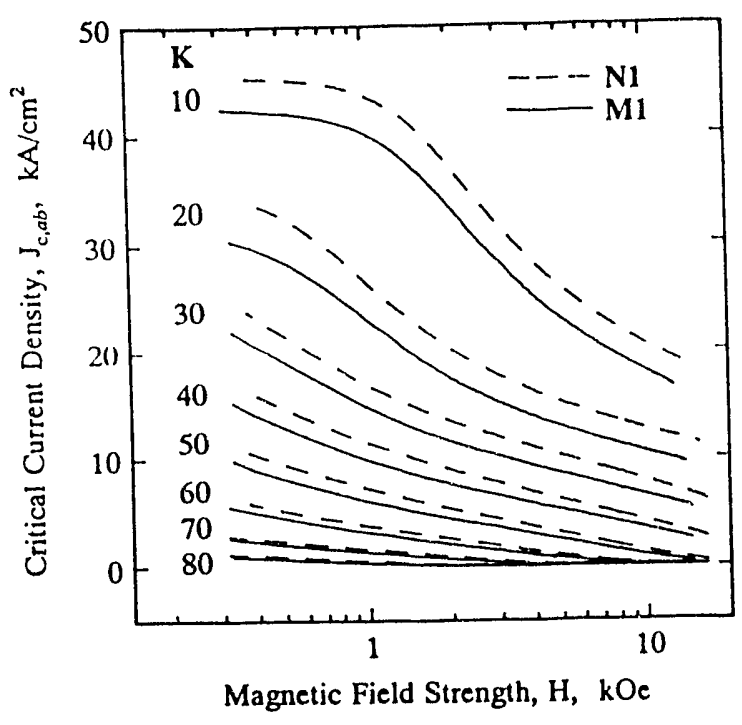

Fig. 6: Magnetic $\mathrm{J}_{\mathrm{c} a b}$ versus $\mathrm{T}$ and $\mathrm{H}$ for PDFRprocess tape $\mathrm{M} 1$ and the N-process tape N1.

\section{Magnetic Critical Current Density}

The magnetic critical current density, $\mathrm{J}_{c a b}$, in the ribbon plane can be calculated from the height, $\Delta \mathrm{M}\left(\mathrm{emu} / \mathrm{cm}^{3}\right)$, of the $M(H)$ hysteresis loop with the aid of the formula $J_{c a b}=\Delta M(20 / W) /\{1-(W / 3 L)\}$, where $L$ and $W(L>W)$ are the length and width of the sample, and the field, $\mathrm{H}_{\perp}$, is applied perpendicular to the plane of the ribbon. The magnetic $J_{c, a b}$ for samples $C$ and $F$ (at $5 \mathrm{kOe}$ ) are plotted versus temperature in Fig. 5 , and those for samples $\mathrm{M} 1$ and $\mathrm{N} 1$ are plotted versus field in Fig. 6. Also inserted in Fig. 5 are a set of $J_{c}(T)$ values for samples M1 and N1 from Fig. 6. In Fig. 5 we note that for $\mathrm{T}>-40 \mathrm{~K} \mathrm{~J}_{\mathrm{c} C \mathrm{C}}>\mathrm{J}_{\mathrm{cF}}$ in agreement with Fig. 4. From this we conclude that the flux-pinning 2212 particles have their greatest influence at elevated temperatures and fields. But in Fig. 6 we note little difference between the $J_{c} s$ of the PFDR- and N-processed samples. That $J_{c, N}$ has risen towards $J_{\text {PFDR }}$, and not the contrary, can be seen by the position of the M1 and N1 data in Fig. 5; in fact this N-processed sample is slightly better than the M1 melt-processed sample. This result is the first indication that 2212-like flux pinning may not be unique to the PFDR process. It seems that variations in the ostensibly normal process can also yield the beneficial 2212 precipitates. These conclusions are corroborated by the irreversibility-field results.

\section{Irreversibility Field}

The M-H behavior of HTSCs is generally reversible throughout a region in $H(T)$ space between $H_{c 2}(T)$ and a locus $H_{r}\left(T_{r}\right)$ where $H_{r}$ and $T_{r}$ are the irreversibility fields and temperatures, respectively. Since the study by Xu and Suenaga (XS) of the temperature dependence of $H_{r}$ in a series of substituted YBCO:123 compounds [36], the irreversibility parameters have become established as useful measures of flux pinning strength. An argument based on flux depinning [37] yielded an $H_{t}$ temperature dependence of the form $H_{r} \sim a(1-t)^{n}$ where $t=$ $\mathrm{T}_{\mathrm{r}}(\mathrm{H}) / \mathrm{T}_{c}(0)$. For substituted YBCO:123, XS demonstrated conclusively a one-to-one relationship between the prefactor "a" and a quantity proportional to the magnetic $J_{c}$ at a given field. For YBCO the index " $n$ " was claimed equal 1.5 [36], and indeed the results of numerous experiments on YBCO [36,37] and both BSCCO:2212 $[38,39]$ and BSCCO:2223 [40] have confirmed that prediction. This is not to say that $n=1.5$ is universally accepted. Some authors have claimed significant departures from that value, for example: $n=4$ in BSCCO:2223 below $-80 \mathrm{~K}$ [41], $\mathrm{n}=3$ in BSCCO:222.3 [42] and TICBCO:2223 [43], $\mathrm{n}=2.19-2.99$ in BSCCO:2223 [44], and $\mathrm{n}$ $=1.17-1.52$ in BSCCO:2212 [45]. But as first indicated by Yamada et al. [41] and later more specifically by de Rango et al. [40] and Shi et al. [46] major departures from the Yeshurun-Malozemoff power-law itself may be encountered in BSCCO:2223 (also in BSCCO:2212 [47]) as the tem serature drops $30 \mathrm{~K}$ or so below $\mathrm{T}_{\mathrm{c}}$. As pointed out by $\mathrm{Ku}$ and Shi [46] at sufficiently high fields $\mathrm{H}_{\mathrm{r}}$ decreases exponentially with temperature due to a gradual breakdown of interlayer proximity coupling. But this exponential temperature dependence seems to be confined to near-monocrystalline and hence very weakly pinned samples [46,47]. It turns out that fully thermomechanically processed PIT BSCCO:2223 exhibits a pure power-law dependence (albeit with $n-3$ ) throughout the entire $H_{8}(T)$ range [29]. 


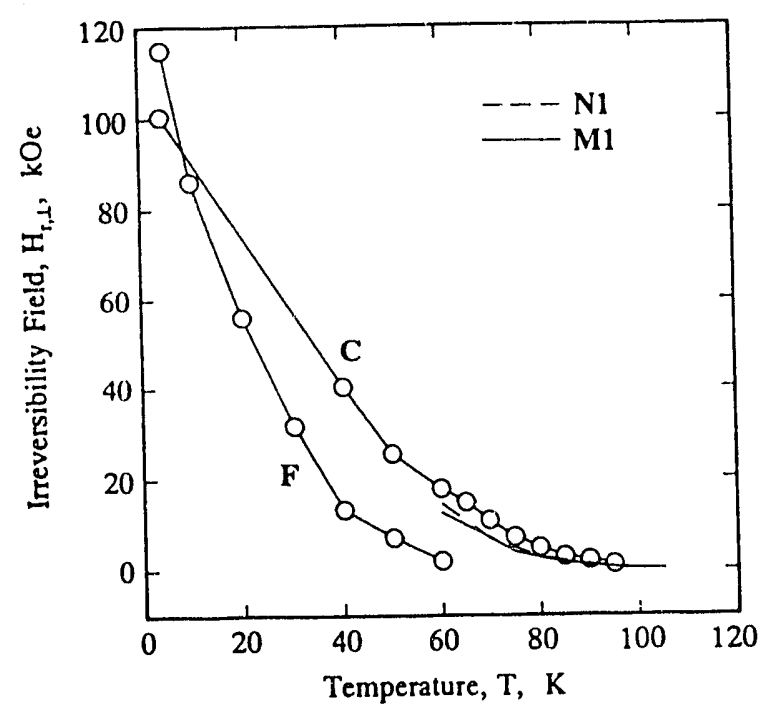

Fig. 7: Irreversibility field, $H_{t, 1}$, versus $T$ for the PDFR-process tape $\mathbf{C}$ and the $\mathrm{N}$-process tape $\mathbf{F}$. Inserted are $H_{t, 1}$ data for $M 1$ and $N 1$.

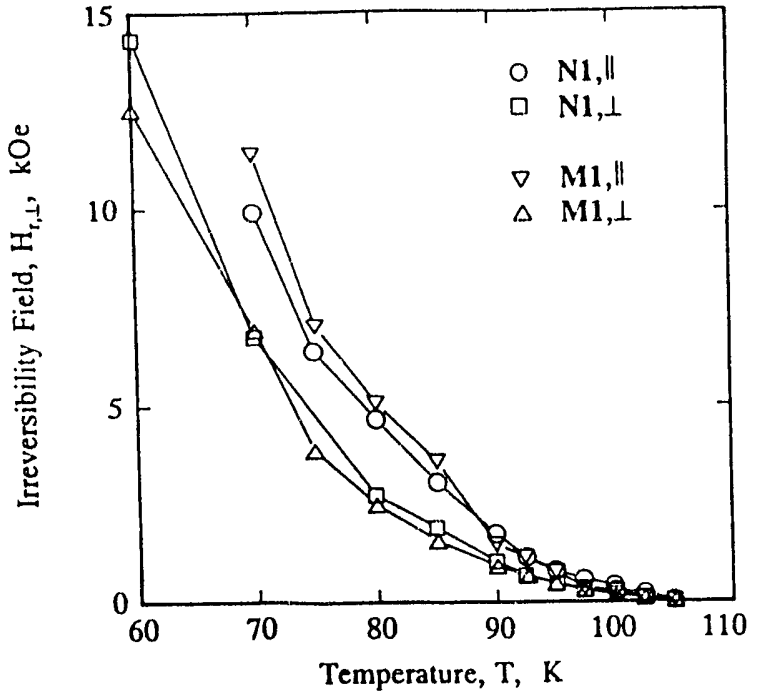

Fig. 8: Irreversibility fields $H_{r, l}$ and $H_{r, \perp}$ (in which $\mathrm{H}$ is $\|$ and 1 , respectively, to the ribbon plane) versus temperature.

No single reason has emerged for the variability of $n$, nevertheless the prefactor a, or position of the irreversibility line in $H(T)$ space, still remains a valid measure of relative pinning strength within a given class of materials.

The results of static magnetization measurements of irreversibility field in samples $\mathrm{C}$ and $\mathrm{F}$ are shown in Fig. 7 . A corresponding set of AC-susceptibility results are to be found elsewhere (for D and E in [29] and C, D, and G in [28]). At temperatures above $-10 \mathrm{~K}$ sample $\mathrm{C}$, with about $10 \% 2212$ phase shows stronger pinning than the precipitate-free counterpart. Figures 7 and 5 contain qualitatively similar pinning-strength information; in both cases the curves cross over at low temperatures. The irreversibility fields for samples M1 and N1 are given in Fig. 8. Just as in Fig. 6, we note little difference between the pinning strengths of those samples. Indeed the response of $\mathrm{H}_{r}$ to change of field orientation is grearer than its response to change of sample. Sets of $H_{r, 1}$ data for samples $\mathrm{M} 1$ and $\mathrm{N} 1$ are plotted in Fig. 7. As before we note that $\mathrm{N} 1$ has risen in pinning strength towards M1 rather than otherwise. For this reason we deduced that the particular variant of the normal process that produced sample $\mathrm{N} 1$ must have resulted in 2212 phase precipitation. Subsequently, $x$-ray diffraction indicated that N1 contained $8-9 \%$ of 2212 , and a member of the M1 batch was found to contain $5-8 \%$ of the precipitate.

$H_{r, L}(T)$ data for samples $M 1$ and $N 1$, fitted to the function $a(1-t)^{n}\left(T_{c}=108.3\right.$ and $107.6 \mathrm{~K}$ respectively) yielded $n$ $=2.97$ (for N1) and 2.89 (for M1) -- values very close to the reported $n=3$ for BSCCO:2223 [29][42].

\section{CONCLUSION}

We have measured the pinning strengths of $\mathrm{BSCCO}$ wires fabricated via several routes using measurements of magnetic $J_{c}$ and irreversibility field, $H_{r}$. The latter follows a (1-t) ${ }^{\mathrm{a}}$ power law throughout the entire field range of 0-14 kOe with indexes $\mathrm{n}$ mostly close to 3 . We find that a fine dispersion of 2212 phase is an effective fluxpinning addition to PIT BSCCO:2223, seemingly regardless of the route used to obtain it. A recommended procedure for introducing the precipitates includes a brief exposure to $860^{\circ} \mathrm{C}$ (during which the conversion $2223 \rightarrow$ 2212 takes place) followed by anneals at $832-836^{\circ} \mathrm{C}$ (during which partial reversion of $2212 \rightarrow 2223$ occurs). It seems that this process has significant potential for optimization in terms of precipitate size and distribution, processing time, and number of thermomechanical process steps.

\section{ACKNOWLEDGEMENTS}

The Battelle research was supported by the Electric Power Research Institute (EPRI) under Contract No. RP8009. 06. Research at the University of New South Wales was supported by Metal Manufacturers, Ltd., and the Commonwealth Dept. of Industry, Technology and Commerce and US-DOE contract W-31-109-ENG-38 


\section{REFERENCES}

[1] M. Suzuki, T. Kimura, and T. Takeshita, Paper presented at the $4^{\text {th }}$ Int. Symp. on Superconductivity, Tokyo, Japan, Oct. 14-17, 1991.

[2] W. Lo and B. A. Glowacki, Adv. Cryo. Eng. Materials 38, 1065-1072 (1992).

[3] Z. Xi, L. Zhou, C. Ji, S. Wu, and Z. Cheng, Adv. Cryo. Eng. Materials 38, 1057-1063 (1992).

[4] K. Ohba, T. Horio, K. Iwasaki, and A. Oota, Supercond. Sci. Technol. 5, S312-315 (1992).

[5] R. Flukiger, A. Jeremie, B. Hensel, E. Seibt, J. Xu, and Y. Yamada, Adv. Cryo. Eng. Materials 38, 1073-1080 (1992).

[6] T. Kitamura, T. Hasegawa, F. Takeshita, K. Yamamoto, S. Murase, and H. Ogiwara, Paper presented at the $4^{\text {th }}$ Int. Symp. on Superconductivity, Tokyo, Japan, Oct. 14-17, 1991.

[7] T. Hikata, M. Ueyama, H. Mukai, et al., Cryogenics 30, 924-929 (1990).

[8] K. Sato, N. Shibuta, T. Hikata, T. Masuda, M. Uyama, T. Kato, and J. Fujikami, Paper presented at the $4^{\text {th }}$ Int. Symp. on Superconductivity, Tokyo, Japan, Oct. 14-17, 1991.

[9] K. Sato, N. Shibuta, H. Mukai, T. Hikata, M. Ueyama, and T. Kato, J. Appl. Phys. 70, 6484 (1991).

[10] M. Ueyama, T. Hikata, T. Kato, and K. Sato, Jpn. J. Appl. Phys. 30 L1384 (1991).

[11] K. Sato, T. Hikata, H. Mukai, M. Ueyama, N. Shibuta, T. Kato, T. Matsuda, M. Nagata, K. Iwata, and T. Mitsui, IEEE Trans. Magn. 271231 (1991).

[12] K. Sato, T. Hikata, M. Ueyama, H. Mukai, N. Shibuta, et al., Cryogenics 31, 687 (1991).

[13] N. Shibuta, M. Ueyama, H. Mukai, and K. Sato, Jpn. J. Appl. Phys. 30, L2084 (1991).

[14] K. Osamura, S. S. Oh, and S. Ochiai, Supercond. Sci. Technol. 3, 143-147 (1990).

[15] K. Osamura, S.S. Oh, and S. Ochiai, Paper presented at the $4^{\text {th }}$ Int. Symp. on Superconductivity, Tokyo, Japan, Oct. 14-17, 1991.

[16] S. Ochiai, K. Hayashi, and K. Osumura, Cryogenics 31, 954 (1991).

[17] T. Kuroda, M. Yuyama, K. Itoh, and H. Wada, Adv. Cryo. Eng. Materials 38, 1045-1051 (1992).

[18] J. Tenbrink, K. Heine, and H. Krauth, Cryogenics 30, 422 (1990).

[19] K. Heine, J. Tenbrink, H. Krauth, and M. Wilhelm, Paper presented at Euromat 91, Cambridge, July 22 27, 1991.

[20] J. Tenbrink, M. Wilhelm, K. Heine, and H. Krauth, JEEE Trans. Magn. 27, 1239 (1991).

[21] K. Heine, J. Tenbrink, H. Krauth, and M. Wilhelm, Adv. Cryo. Eng. Materials 38, 1033-1040 (1992).

[22] D. Y. Kaufman, M. T. Lanagan, S. E. Dorris, J. T. Dawley, et al., Applied Supercond. 1, 81-91 (1993).

[23] J. S. Luo, N. Merchant, A. V. Moroni, D. M. Gruen, et al., Applied Supercond. 1, 101-107 (1993).

[24] L. R. Motowidlo, E. Gregory, P. Haldar, J. A. Rice, et al., Appl. Phys. Lett. 59, 736-738 (1991).

[25] P. Haldar, J. G. Hoehn, Jr., J. A. Rice, and L. R. Motowidlo, Appl. Phys. Lett. 60, 495-497 (1992).

[26] P. Haldar and L. Motowidlo, JOM, pp. 54-58, October 1992.

[27] S. X. Dou, H. K. Liu, Y. C. Guo, and P. Munroe, Physics C 190, 157-159 (1991).

[28] S. X. Dou, H. K. Liu, Y. C. Guo, J. Wang, X. J. Jin, and Q. Y. Hu, Proc. $3^{\text {rd }}$ World Congr. Superconductivity, 14-18 Sept., 1992, Munich, Germany.

[29] S. X. Dou, Y. C. Guo, and H. K. Liu, Physica C 194, 343-350 (1992).

[30] S. X. Dou, H. K. Liu, Y. C. Guo, and C. C. Sorrell, Supercond. Sci. Technol. 5, S471 (1992).

[31] S. X. Dou, H. K. Liu, Y. C. Guo, Appl. Phys. Lett. 602929 (1992).

[32] Y. C. Guo, H. K. Liu, and S. X. Dou, Applied Superconductivity 1, 25-31 (1993).

[33] Y. C. Guo, H. K. Liu, and S. X. Dou, Physica C 200, 147 (1992).

[34] S. Sengupta, Donglu Shi, S. Salem-Sugui, Jr., Z. Wang, et al., J. Appl. Phys. 72, 592-595 (1992).

[35] H. W. Weber, in Critical Current Limitations in High Temperature Superconductors, M. Baran et al., eds. (World Scientific, Singapore, 1992) pp. 3-16, 239-245.

[36] Y. Xu and M. Suenaga, Phys. Rev. B 43, 5516-5525 (1991).

[37] Y. Yeshurun and A. P. Malozemoff, Phys. Rev. Lett. 60, 2202-2205 (1988).

[38] B. D. Biggs, M. N. Kunchur, J. J. Lin, et al., Phys. Rev. B 39, 7309-7312 (1989).

[39] C. Quitmann, U. Ebels, P. C. Splitigerber-Hünnekes, et al., Physica B 165\&166, 1143-1144 (1990).

[40] P. de Rango, B. Giordanengo, J. L. Genicon, et al., Physica B 165\&166, 1141-1142 (1990).

[41] Y. Yamada, S. Murase, K. Yamamoto, and Y. Kamisada, Cryogenics 30, 581-585 (1990).

[42] A. Nishada and K. Horai, Solid State Comm. 74, 947-950 (1990).

[43] Y. Wolfus, Y. Yeshurun, and I. Felner, Phys. Rev. B 39, 11, 690-11,694 (1989).

[44] J. B. Shi, P. L. Kuo, B. S. Chiou, and H. C. Ku, Physica C 185-189 2143-2144 (1991).

[45] L. W. Lombardo, D. B. Mitzi, A. Kapitulnik, and A. Leone, Phys. rev. B 46, 5615-5620 (1992).

[46] H. C. Ku and J. B. Shi, in Superconductivity and its Applications, Y. H. Kao et al., eds. (Amer. Inst. Phys., NY, 1992) pp. 467-476.

[47] E. W. Collings, M. D. Sumption, Y. Higashida, and K. Michishita, paper on BSCCO:2212 in this proceedings. 

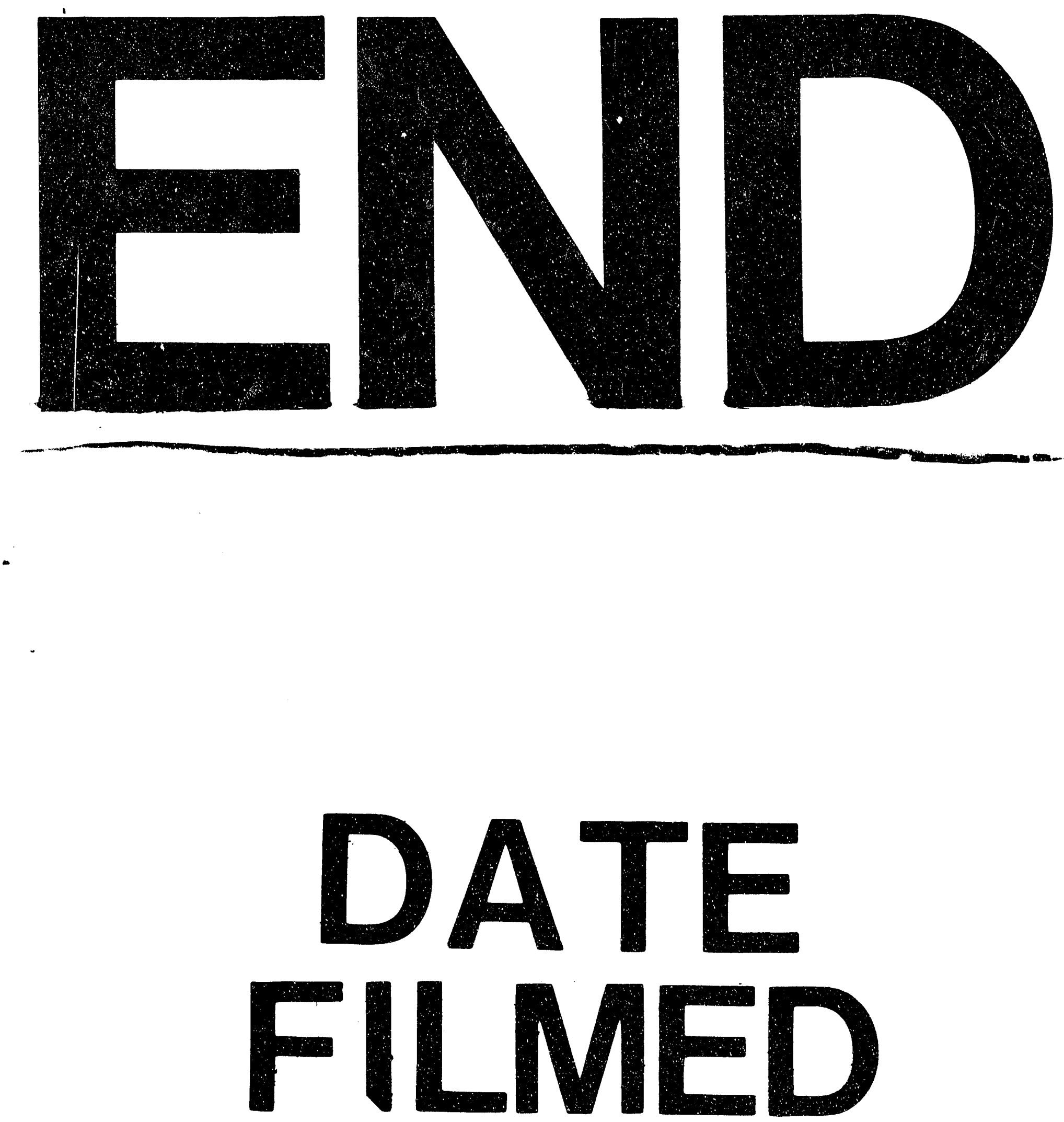

$$
\begin{array}{l|l|l}
4 & 28 / 93
\end{array}
$$


$m$ 